\title{
IMÁGENES Y MEMORIA: EL USO SOCIAL DE LAS FOTOGRAFÍAS EN LA REELABORACIÓN DE UN PASADO COMUNITARIO
}

\author{
Marcela Brac ${ }^{1}$
}

\section{Introducción}

Este artículo forma parte de una investigación sobre: el proceso de reconversión productiva, forzosa, que afectó a poblaciones situadas en el Chaco santafesino ${ }^{2}$. La puesta en producción, de la franja boscosa, se remonta al último cuarto del siglo XIX, cuando se inicia la explotación de quebracho colorado ${ }^{3}$ para la elaboración de tanino. El agotamiento del recurso natural provocó el cierre acelerado de las fábricas, y en consecuencia sucedieron cambios violentos en las condiciones de vida de los pobladores, quienes fueron constreñidos a una emigración por causas económicas. En el caso de Villa Guillermina, localidad de estudio, el cierre de la fábrica en 1952, forzó el éxodo de la mayoría de la población.

En la actualidad y en el marco de una política pública provincial, de recuperación del patrimonio forestal, se produce una serie de actividades con el propósito de "rescatar el pasado" de localidades surgidas como consecuencia de la actividad foresto- industrial. En este contexto analizo el trabajo de gestión de memorias, en el cual algunos pobladores de Villa Guillermina desempeñan un rol protagónico. La Asociación de Rescate de la Cultura Forestal es una institución conformada por pobladores de diferentes generaciones; algunos trabajaron para La Forestal ${ }^{4}$, en el pueblo obrero, otros son descendientes de primera y segunda generación de esos trabajadores. Resulta interesante observar la ausencia, entre sus integrantes, tanto de ex trabajadores de los obrajes como de sus descendientes.

La Asociación llevó adelante la creación de un museo para dar cuenta del pasado del pueblo, desde sus orígenes hasta el cierre de la fábrica. En el siguiente relato un integrante manifiesta los propósitos de la institución:

\footnotetext{
${ }^{1}$ Universidad de Buenos Aires, Argentina.

${ }^{2}$ El quebracho colorado se encuentra en la zona oriental húmeda del parque chaqueño, penetra en el nordeste de la provincia de Santa Fe formando una cuña, que recibe el nombre de Cuña Boscosa santafesina.

${ }^{3}$ Quebracho. (De quebrar y hacha) m. Nombre genérico de varias especies botánicas de árboles americanos de madera muy dura. 2.Arg., Bol. y Par. Árbol de gran porte, de la familia de las Anacardiáceas, con cuya madera, muy dura, se fabrican durmientes. Su corteza es rica en tanino.

${ }^{4}$ Compañía de Tierras, Maderas y Ferrocarriles La Forestal Ltda., dedicada a la producción de tanino y su comercialización.
} 
(...) Nosotros queremos aprovechar lo que quedó de La Forestal, aprovechar la historia de La Forestal potenciarla y ofrecerla como turismo, esa es la idea.

(Integrante de la Asociación de Rescate de la Cultura Forestal).

En un nuevo escenario con posibilidades turísticas se proyectó la creación del Museo, como espacio autogestionado por los pobladores, allí las fotografías desempeñan un papel destacado; a través de ellas se reconstruye un relato unificado y de carácter oficial sobre el pasado forestal de Villa Guillermina.

\section{Algunos antecedentes históricos}

La industria tánica, en la región, revistió la forma de producción a término; con altas concentraciones de capital y mano de obra. La Forestal, empresa que monopolizó la industria del tanino en Argentina, impulsó la colonización de la zona; trabajadores provenientes de: Corrientes, Chaco y Paraguay llegaron a los montes ${ }^{5}$ de quebracho colorado motivados por las oportunidades laborales que ofrecía la empresa. Se formaron cinco pueblos obreros, algunos albergaron hasta cinco mil pobladores, la cantidad de habitantes dependía de la envergadura de cada fábrica. Hacia la primera década del siglo XX se había configurado un paisaje industrial que comprendía: fábricas, ferrocarriles, puertos y pueblos obreros.

Los pueblos disponían de servicios públicos y actividades de ocio al igual que las urbes más importantes de la región. La colonización y la modernidad arribaron de la mano de una empresa extranjera; y en cierto grado las instituciones estatales -escuelas, juzgado de paz, cuerpo de policía- también fueron introducidas por mediación de la empresa. Sin embargo, este gran emprendimiento moderno entrañaba su fecha de clausura.

La actividad forestal se constituyó como eje productivo predominante de la zona, la configuración social de las poblaciones que allí surgieron respondieron a la lógica de valorización del capital a corto plazo. El modelo predominante fue de enclave productivo, que se mantuvo hasta los primeros años de la década del cincuenta, cuando se inicia el proceso de desinversión de capital (Balazote et al, 2009).

\footnotetext{
${ }^{5}$ El quebracho colorado generalmente se encuentra junto a otras especies arbóreas, formando una masa boscosa intrincada y tupida, con presencia de arbustos. En términos generales se trata de un bosque cerrado de dificultoso acceso, y por estas características, usualmente, se lo denomina monte.
} 
El poblamiento de la zona respondió a las necesidades de este modelo productivo que diagramó: centros urbanos fabriles, y otros de carácter secundario que cumplían la función de proveedores de materia prima. Las fábricas fueron construidas en áreas próximas a los bosques de quebracho colorado, y cercanas a una línea férrea. De este modo, se fue conformando un paisaje propio a la nueva dinámica productiva, donde fábricas y vías férreas fueron abriendo la espesura del monte chaqueño, movilizando a su entorno un nutrido mercado laboral.

La ocupación espacial operó fundamentalmente bajo dos modalidades: pueblos forestales y obrajes. La industria tánica, a gran escala, requirió de infraestructura adecuada para la producción y también habitacional destinada a la contención de mano de obra. Los pueblos surgidos en los dominios de La Forestal respondían a un patrón uniforme; la diferencia habitacional se correspondía con la jerarquía laboral, el espacio habitacional reforzaba la jerarquía establecida en el proceso de producción.

Las fábricas internadas en los montes de quebracho colorado, representaron para muchos hombres y mujeres la posibilidad de obtener trabajo, vivienda y una vida de bienestar y progreso. Sin embargo, la mayoría de los trabajadores vinculados a la empresa, trabajaban en obrajes donde las condiciones de trabajo y de vida cotidiana eran totalmente opuestas a la de sus pares en las fábricas.

La vida en los obrajes estaba sujeta a las necesidades y ritmos de las fábricas. La dinámica de trabajo, en el monte, implicaba desplazamiento continuo de los trabajadores y sus familias; proyectando de este modo un poblamiento rural efímero y precario. El obraje como unidad económica productiva primaria, estaba conformado por trabajadores que en base a su destreza y especialidad realizaban tareas claramente diferenciales. El trabajo rural agrupaba a: hacheros, carreros, boyeros, fleteros, peones de playa de estacionamiento de madera, balanceros. El término obrajero fue utilizado para designar, de forma genérica, a todos estos trabajadores del ámbito rural forestal.

El trabajo en el obraje, relacionado con la extracción de materia prima, significaba: jornadas laborales extenuantes, trabajo a destajo, condiciones laborales y habitacionales precarias, aprovisionamiento compulsivo de mercaderías y desplazamiento incesante del trabajador y su grupo familiar. Los obrajeros superaban en número a los trabajadores industriales, tenían la responsabilidad de abastecer constantemente a las fábricas, sobre su 
producción se asentaba el éxito de la empresa forestal. Así lo recuerda un trabajador de los obrajes.

(...) nosotros, los del obraje, éramos los últimos para la Compañía, y sin embargo nosotros estábamos haciendo la producción, si no la fábrica no marcha. Miles estábamos en el monte trabajando para la fábrica, y sin embargo no nos daban importancia, nos tenían como que éramos un animal, muchas veces nos trataban como si fuéramos un perro.

(Testimonio de un ex hachero).

Es importante tener presente la variedad de experiencias laborales con la empresa para observar: en qué medida se integran o no, memorias desiguales de ese pasado en una versión unificada.

\section{Emprendedores de memorias}

La Asociación de Rescate de la Cultura Forestal, es una institución con personería jurídica, si bien fue gestionada desde la comunidad, su emergencia está relacionada a un proyecto de recuperación de patrimonios locales, impulsado desde políticas públicas provinciales, con el propósito de crear nuevos circuitos turísticos ${ }^{6}$.De este modo, las primeras actividades, de la Asociación, se inscriben en este plan estratégico de turismo emergente, impulsado por la Secretaría de Turismo de la Provincia de Santa Fe. Actualmente los turistas que recibe el pueblo, en su gran mayoría escolares, realizan viajes de estudio para conocer la historia de la industria del quebracho colorado, y las condiciones de vida de un pueblo forestal.

En el año 2004 la Comisión de Rescate de la Cultura Forestal, (actualmente Asociación), presentó un proyecto, en la Secretaría de Cultura de la Provincia de Santa Fe, proponiendo la creación del "Campamento Cultural Corazón de Quebracho" como modalidad de turismo escolar. Dos años después, por medio de un decreto provincial, comenzó a funcionar este Campamento. Su creación generó puestos de trabajo para jóvenes del pueblo, integrantes de la Asociación, quienes se desempeñan como animadores culturales. Todas las semanas, durante el año escolar, el Campamento recibe grupos de

\footnotetext{
${ }^{6}$ Villa Guillermina integra el circuito turístico denominado "Camino del Tanino-Pueblos Forestales". En otro trabajo analicé la integración de los pueblos forestales a la incipiente actividad turística. Brac (2011).
} 
escolares; y los animadores culturales realizan con ellos diferentes actividades didácticas, entre las que se encuentra la visita al Museo.

El Museo integra el circuito turístico por el pueblo, el recorrido comprende los sitios considerados más representativos de lo vida de un ex un pueblo forestal. La fábrica, el hospital forestal, clubes, escuelas, iglesia, edificios que pertenecieron a los almacenes de ramos generales de la empresa, la plaza histórica. Durante el recorrido la/el guía comenta el origen y función de cada edificación. Por ejemplo, indica dónde residía el gerente de la fábrica; que función cumplía la Casa de Visitas; muestra la diferencia de los clubes (uno para los jerárquicos y otro para los obreros); señala por dónde pasaban las vías del tren; y explica la complejidad del hospital forestal. Por medio de un relato descriptivo y con la ayuda de algunos vestigios materiales, que aún se conservan, se busca reconstruir la vida cotidiana del pueblo obrero en el siglo pasado. Como menciona una de las animadoras cultuales que guía el recorrido de los estudiantes.

(...) la idea es que ellos dimensionen que era este pueblo hace 80 años atrás. Pero bueno yo lo voy contando, pero como siempre digo esto se materializa cuando ellos ven las imágenes. Entonces ahí dicen: "ah lo que me contaron entonces es cierto". Por eso siempre trato de decirles imagínense, sueñen, piensen en la gente que caminaba por acá, la gente que bailaba, la gente que miraba cine, el teatro, el tren. El ruido de los trenes, y hoy silencio; y quedan como asombrados porque te dicen: “¿un tren acá?"

(Animadora cultura, realiza las visitas guiadas por los circuitos turísticos del pueblo).

El recorrido finaliza con el arribo al Museo, allí el escolar-visitante se encuentra con información compilada y ordenada sobre el pasado de Villa Guillermina.

En este contexto, de emergencia de memorias de la época forestal, y teniendo en cuenta el público destinatario del mensaje, analizo: el uso social de las fotografías exhibidas en el Museo; y la conformación en un relato hegemónico acerca del pasado de la comunidad. Asimismo indago sobre los silencios que tensionan el relato, y las ausencias de imágenes.

En la reconstrucción del pasado se recurre a la metáfora de la "gran familia" que sufre una desintegración trágica, la cual sumergió al pueblo en un profundo estado de languidez. La paralización de la fábrica representa una ruptura traumática para los pobladores, el éxodo de cientos de: compañeros, amigos, familiares y vecinos. Este hecho 
es utilizado para señalar dos períodos relevantes en la trayectoria comunitaria que son verbalizada con las expresiones: "en la época de La Forestal" y "después de la Forestal".

De esta manera, la historia de Villa Guillermina está atravesada por un antes y un después de ese acontecimiento. Los recuerdos, asociados a la etapa previa al cierre de la fábrica, son sobrevalorados y organizados en dos grandes temáticas: "trabajo seguro y buen vivir", así los sujetos sintetizan y expresan sus experiencias pasadas.

El propósito actual de los organizadores del Museo es: reconstruir el pasado comunitario del pueblo teniendo en cuenta las experiencias de sus pobladores. En este sentido trabajan en la recopilación, organización y sistematización de testimonios de hombre y mujeres que vivieron ese período histórico. El director de la Asociación sostiene que su trabajo consiste en contar: "la otra parte de la historia que no se contó".

Queremos contar lo que no se contó de La Forestal, lo que vivió la gente y que no está en los libros.

(Presidente de la Asociación de Rescate de la Cultura Forestal).

Recurriendo a la definición de Iréne Jonas, sobre el álbum de familia como expresión del recuerdo social, me propuse abordar el análisis de las fotografías exhibidas en el Museo y de la muestra en general, que también comprende objetos y mobiliario de la época, al estilo de un álbum de familia. Cada sala despliega, una hoja, con información seleccionada para comunicar a los visitantes foráneos, pero a su vez para evocar recuerdos y sentimientos en los pobladores.

Las fotografías enmarcadas, que cuelgan en las paredes, han sido seleccionadas cuidadosamente por los organizadores de la muestra; ellas son presentadas como testigos del pasado que se pretende reconstruir.

Jonas, sostiene que el álbum de fotos de familia ofrece la posibilidad de reflexionar sobre lo que muestran por medio de su construcción selectiva, pero también nos invita a indagar sobre lo ausente.

Eles evocam e transmitem a lembrança de elementos que merecem ser conservados, respeitados e incorporados à memória familiar. (...) Se a seleção de certas imagens e a construção de uma mise-en scène que o álbum memoriza permitem que se reaprenda a história ficcional ou real de tal ou tal família, elas permitem, igualmente, muito mais a se ver.

(Jonas, 1996: 105) 
Entonces, qué se desea conservar y transmitir del pasado, y por qué. En este Museo las fotografías se constituyen como elementos probatorios, para dar cuenta de un pasado de esplendor perdido para siempre. La selección de las imágenes está en relación con la versión del pasado que los pobladores quieren transmitir, un pasado de trabajo y bienestar social. En el recorrido se evidencia un esfuerzo por establecer continuidad con esos recuerdos, y distanciarse de los recuerdos trágicos -huelgas, persecuciones, enfrentamientos sangrientos con la patronal, muertes, paralización de fábricas, éxodo poblacional- que han signado la trayectoria histórica de la comunidad, y por los cuales han sido visualizados por la sociedad en general.

Ante un imaginario social dónde la historia de La Forestal quedó instituida de forma negativa, y que el cine difundió por medio de la película "Quebracho", las imágenes del Museo fueron seleccionadas para narrar "otra historia", para presentar a los testigos de ese pasado de bienestar social. En la construcción social de este relato se sobredimensionan algunas experiencias pasadas, relacionadas con el trabajo y las actividades de ocio. El propósito es: representar un pueblo obrero próspero, moderno, pujante, y contraponer esta imagen con otras localidades vecinas que en aquel tiempo carecían de adelantos técnicos. Como lo expresó un poblador:

(...) sabe porque quiero destacar tanto la historia, porque durante cincuenta años que vino esta empresa a explotar el quebracho, este norte vivió una vida social distinta (...) la gente vivía en aquel entonces al estilo europeo con los mejores adelantos técnicos, cuando en otras localidades alrededor de Santa Fe recién empezaban con el arado.

(Poblador)

En este sentido, las fotografías del Museo son presentadas como testigos de ese pasado. Al exhibirlas, los organizadores de la muestra, buscan dar cuenta de un pueblo moderno formado por trabajadores del tanino. Enfatizan en los adelantos técnicos como: energía eléctrica, agua potable, infraestructura propia de las grandes urbes. Destacan todo aquello que no está presente en la actualidad -o que ya no cumple la función que tuvo originariamente-, pero que existió alguna vez. En este ejercicio de evocación del pasado los recuerdos cumplen la función de otorgar sentido al presente de la comunidad, porque

\footnotetext{
${ }^{7}$ Película dirigida por Ricardo Wullicher. Año de estreno 1974.
} 
aluden a los orígenes en los que esta se reconoce. Como sostiene Ricoeur: "Lo que honramos del pasado no es el hecho de que ya no existe más, sino el hecho de que alguna vez existió" (Ricoeur, 2002: 28).

Por medio de las fotografías intentan reforzar el mensaje que quieren comunicar sobre los orígenes del pueblo, que sintetizan con la expresión "Guillermina era una perla en medio del monte santafesino”. Las fotografías dispuestas en el Museo con el propósito de evocar "los buenos recuerdos", han sido seleccionadas en la medida que habilitan a la reconstrucción de esas memorias. La lógica de clasificación de las fotografías evidencia un esfuerzo por establecer una línea de continuidad entre ese pasado de bienestar social, y el presente marcado por carencias materiales, por la apremiante falta de trabajo principalmente para los pobladores más jóvenes.

Una ojeada por las salas.

El Museo tiene cinco salas, cada una organizada en base a una temática principal. El recorrido se inicia en la primera sala con la fotografía del empresario que le dio nombre al pueblo, en honor a su esposa Guillermina, a continuación sigue una foto de ella, y luego de su hijo. Estas tres fotos, dispuestas de forma escalonada, son de las pocas que aparecen individualizadas; el relato sobre el pueblo obrero se inicia por la familia del "fundador". En la misma pared se encuentran otras fotografías de familias trabajadoras, aquí desaparece la identificación personalizada de cada integrante del grupo, y fue colocado al pie de la misma el apellido de la familia.

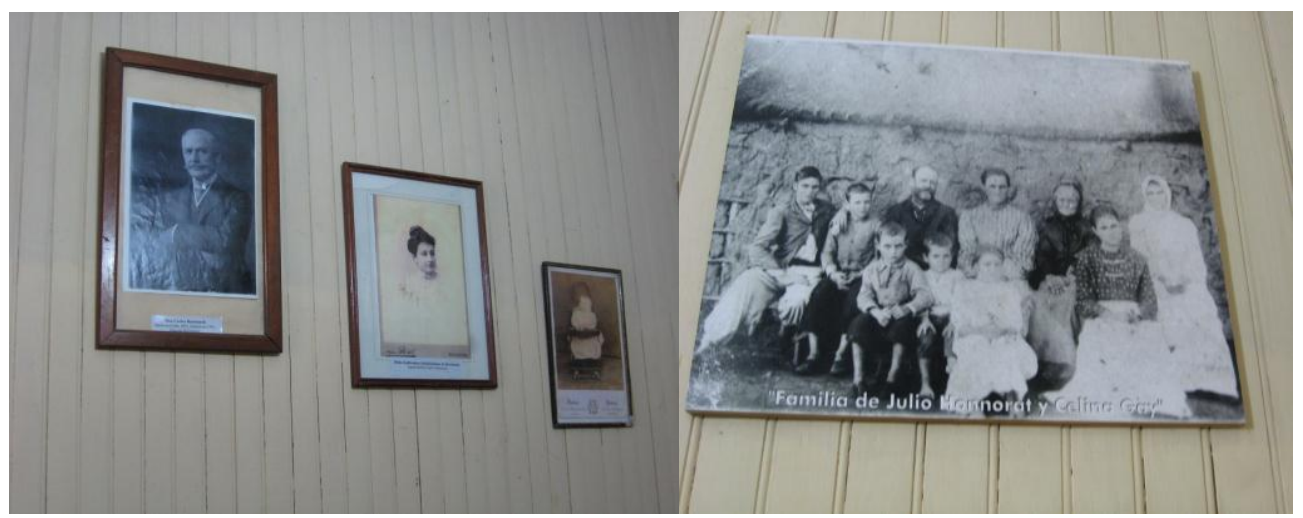




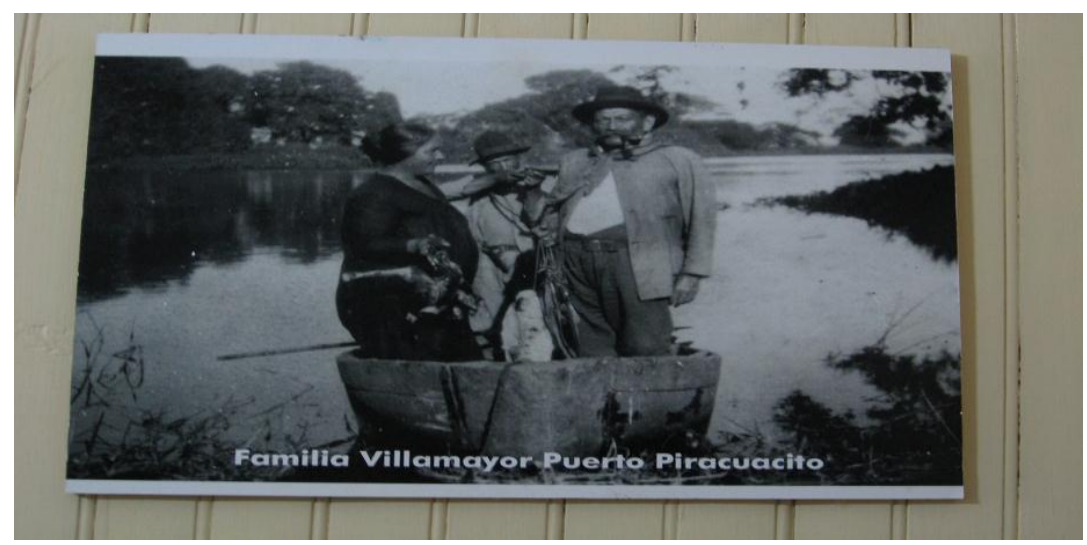

Estas fotografías se encuentran en la primera sala.

$* * *$

Luego de la presentación de estas fotos, la guía continúa el relato con las fotografías que se encuentran desplegadas en la pared contigua: la fábrica; un grupo de obreros; el ferrocarril; policías; trabajadores-pobladores en el almacén de ramos generales; plantel del hospital forestal; escuelas, y la iglesia. El relato se centra en las actividades laborales desarrolladas en el pueblo, y hace referencia a la organización de la villa obrera. En este sentido se remarca: la presencia de la escuela, por la importancia que la empresa otorgaba a la educación de los hijos de los trabajadores, y al hospital forestal como "beneficio" proporcionado por la empresa a sus trabajadores. 


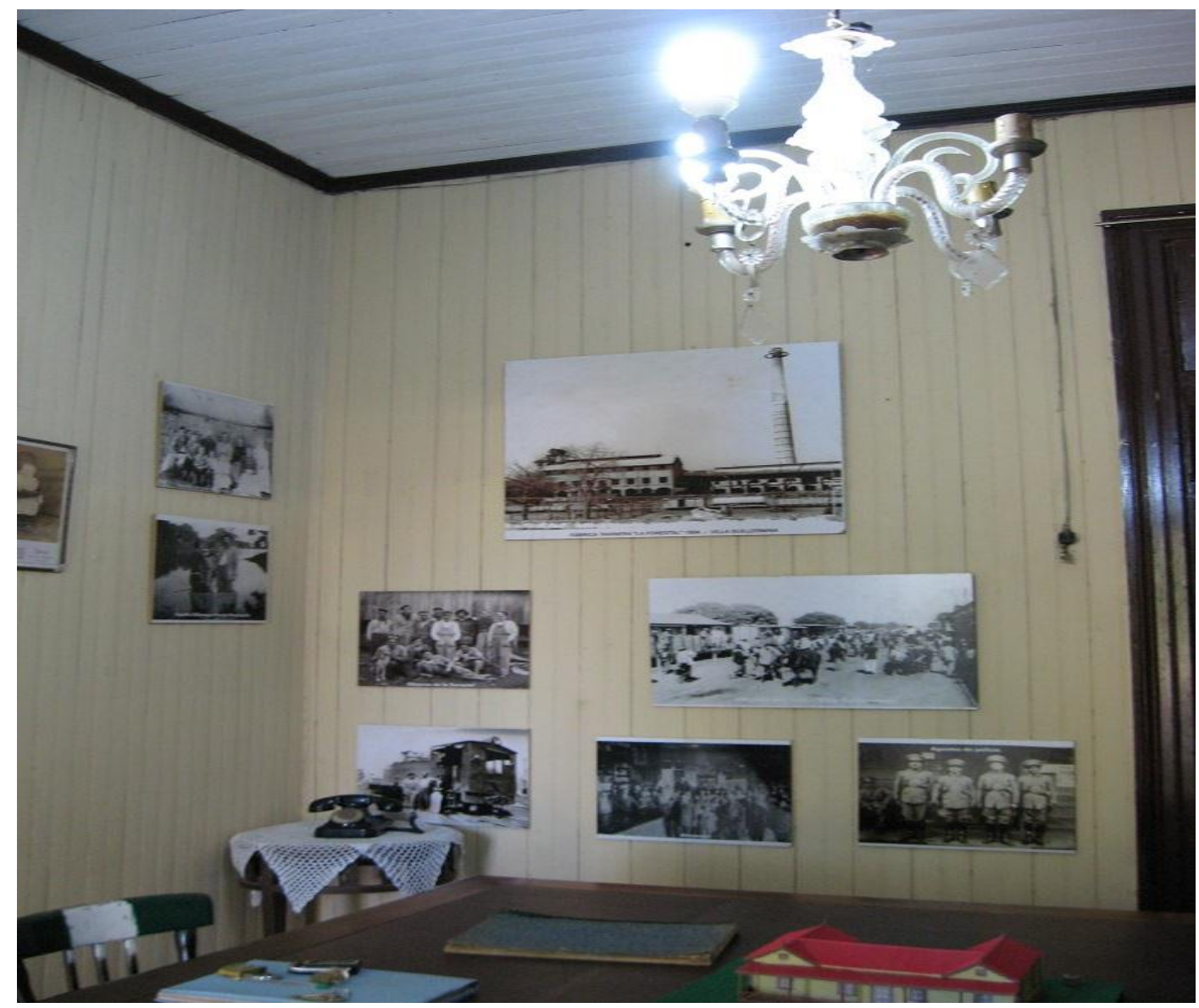

Ubicación: primera sala.

Las fotografías son utilizadas también para evocar las pérdidas, sirven para dar testimonio de la desaparición de ese universo laboral que se conformó en torno a la fábrica. Al referirse puntualmente a la fotografía identificada con el nombre "Familia Villamayor, Puerto Piracuacito", la guía dice: "esta familia vivía en el puerto, porque acá en esa época teníamos puerto”. Esa misma expresión se reitera con otras fotografías, una donde se puede observar a tres hombres posando en la locomotora del tren, y otra tomada al plantel del hospital, ambas son presentadas por la guía de la siguiente manera: "en esa época, teníamos tren....", "en esa época, teníamos un hospital de alta complejidad..." 


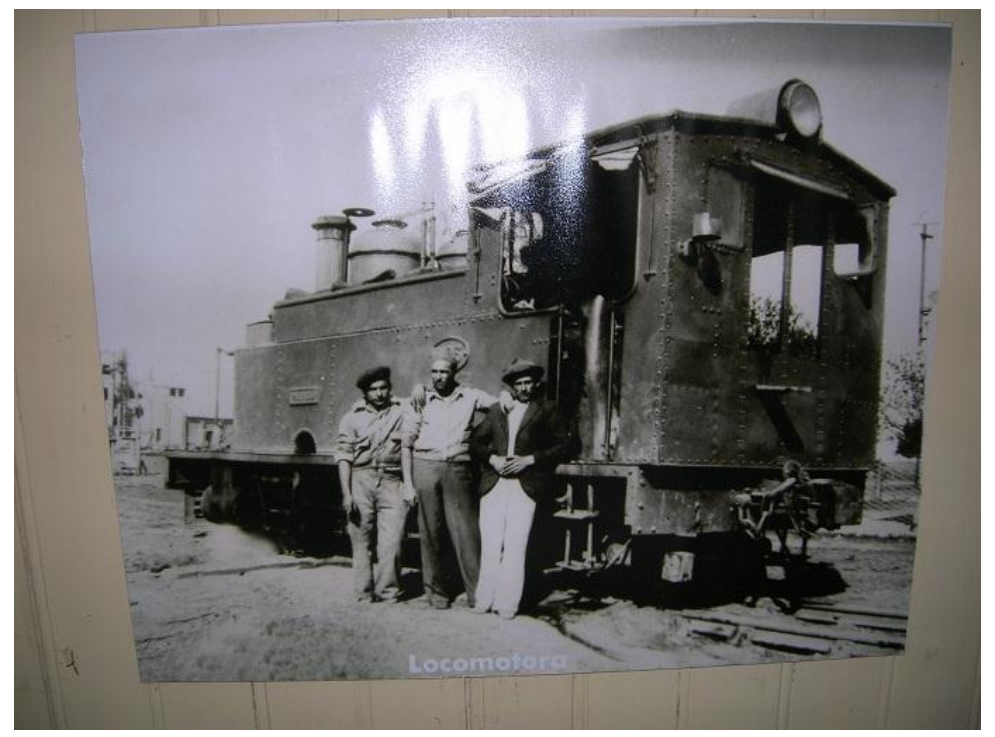

Ubicación: primera sala.

En la misma sala, se encuentra una fotografía que hace referencia al trabajo en el obraje. Es la única fotografía que aparece en esta sala -y como veremos más adelante en todo el Museo- que evoca el trabajo rural. Llama la atención su ubicación, se encuentra distante del cuerpo principal de fotografías que orientan el relato. La fotografía es de un carro cahapé, instrumento de trabajo que tirado por bueyes, se utilizaba para transportar los rollizos de quebracho colorado desde el lugar de explotación hasta las playas de estacionamiento. El carrero transportaba la carga hasta la playa de embarque más cercana. Este trabajo requería mucha destreza, principalmente cuando las lluvias estropeaban los caminos y dificultaban la circulación. La fotografía que se muestra es la del carro vacío, sin bueyes, sin carga, sin su conductor. 


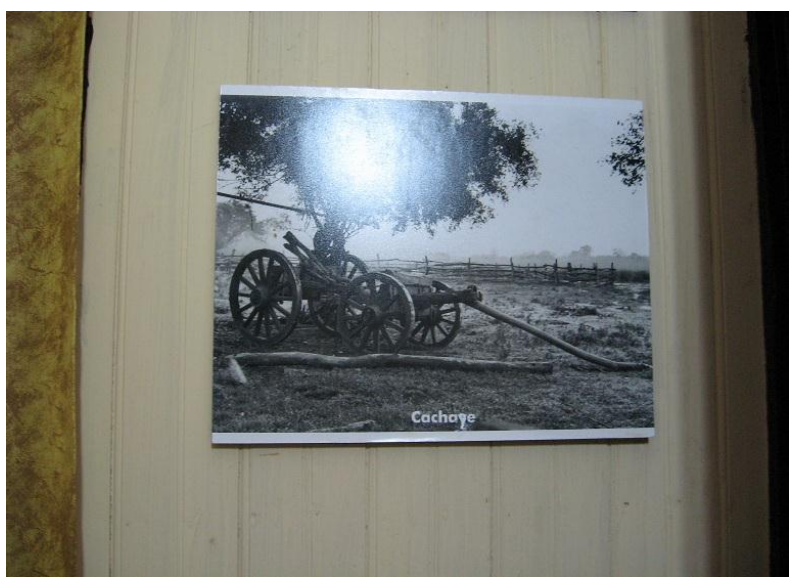

Ubicación: Primera sala.

El recorrido continúa por una sala temática que posee fotografías y objetos relacionados con espacios de sociabilidad. La propuesta es comunicar las actividades recreativas, como fiestas sociales y actividades culturales, propiciadas por la empresa.

A continuación, en otra sala se agrupan objetos que hacen referencia a la variedad de deportes practicados en el pueblo como: golf, tenis, ciclismo, tiro, básquet, fútbol, y se exhiben fotografías de los diferentes equipos de clubes deportivos femeninos y masculinos.

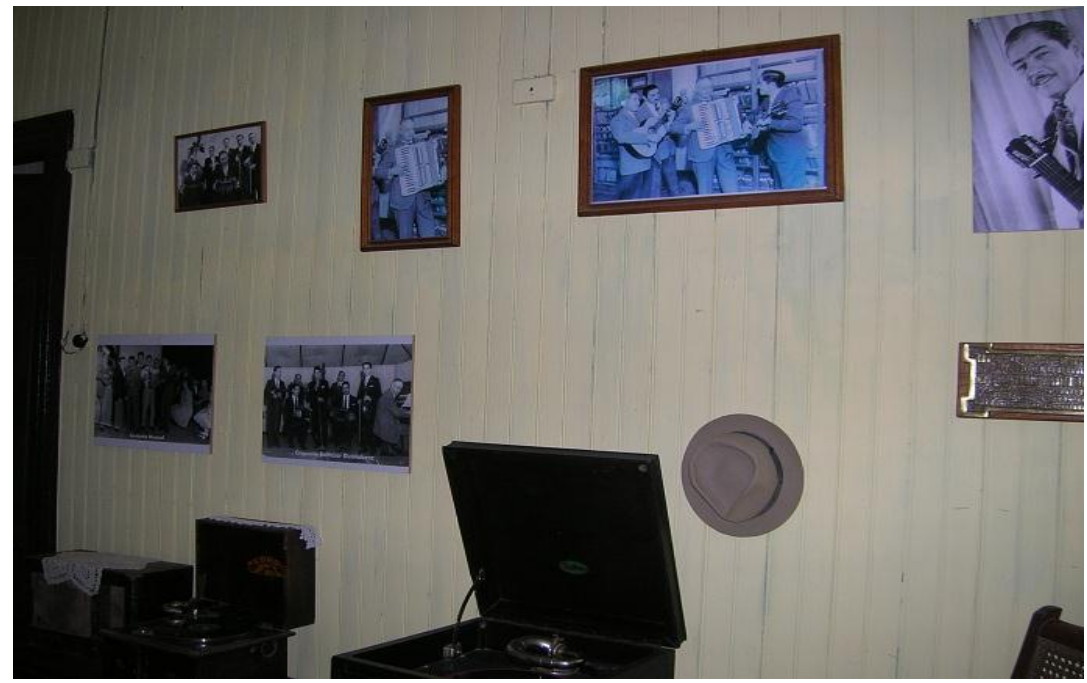

Ubicación: segunda sala. 


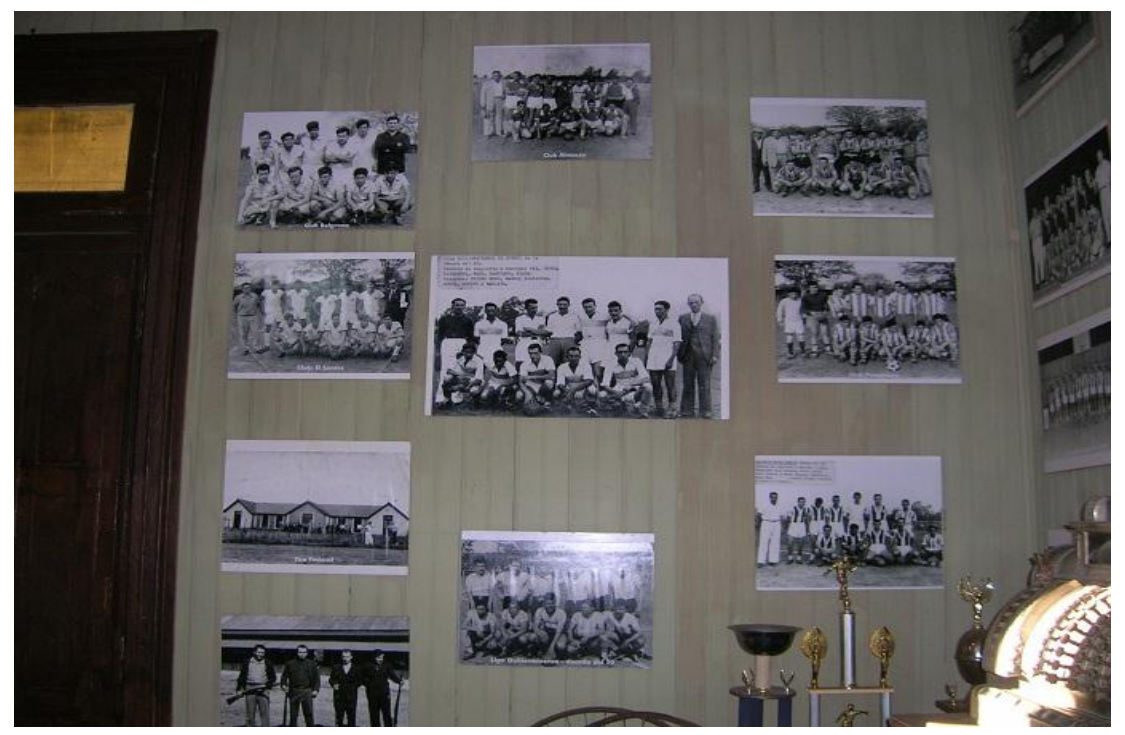

Ubicación: tercera sala.

En la cuarta sala que dispone de pocas fotografías, es interesante observar la conexión de tiempo y espacio entre las fotografías allí expuestas. Una de ellas muestra a la esposa del "fundador" en Alemania. Otras muestran a exploradores europeos en el monte chaqueño guiados por aborígenes, y a las primeras familias radicadas en la zona. Estas fotografías sirven para mencionar el período exploratorio previo a la construcción de la fábrica y el pueblo. En otro sector se exhibe una maqueta de la fábrica, y junto a ella una fotografía de trabajadores en los talleres de reparación de vagones del ferrocarril. Actividad que se inicia luego del cierre de la fábrica, y de éxodo de la empresa del país. También, se exhibe la fotografía de un rancho abandonado luego del éxodo. En esta sala se hace hincapié, a través de las imágenes, en el período inicial de la "época forestal”, y en la etapa que se inicia después de la desintegración de la industria forestal. 

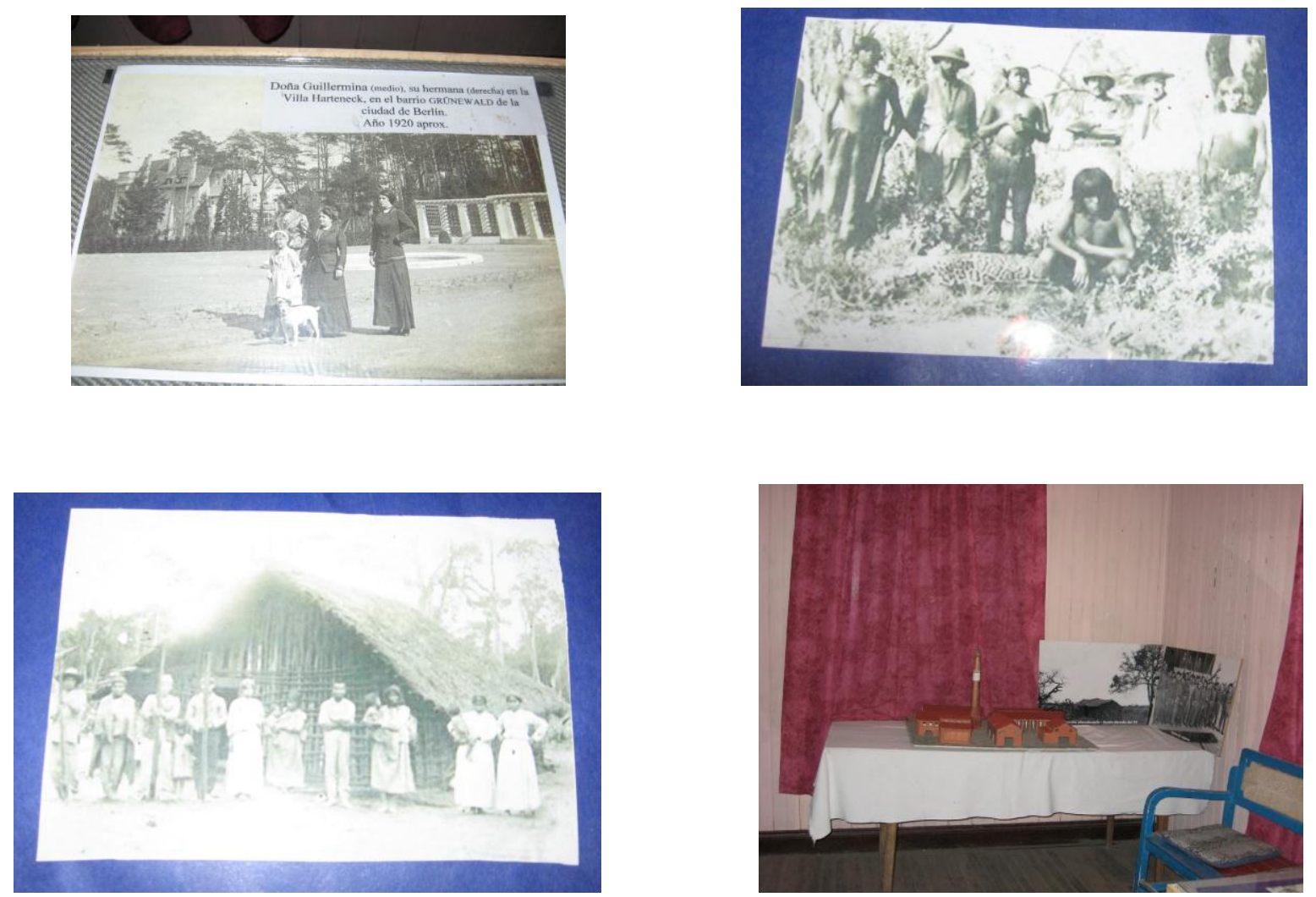

Ubicación: cuarta sala.

La quinta sala exhibe algunos elementos de trabajo rural; allí se reserva un espacio para evocar a los trabajadores del monte. Resulta interesante observar por un lado, la temática elegida para concluir con el recorrido, y por el otro el cambio en la dinámica fotografías-relato que se venía manteniendo.

Luego de visitar cuatro salas, que exhiben fotografías donde los visitantes pueden reconocer rostros, y en algunos casos hasta reconocer el propio, se arriba a este último recinto sin fotografías, donde el blanco intenso de las paredes vacías remarca los silencios y las ausencias en la reelaboración de estas memorias.

$$
* * *
$$




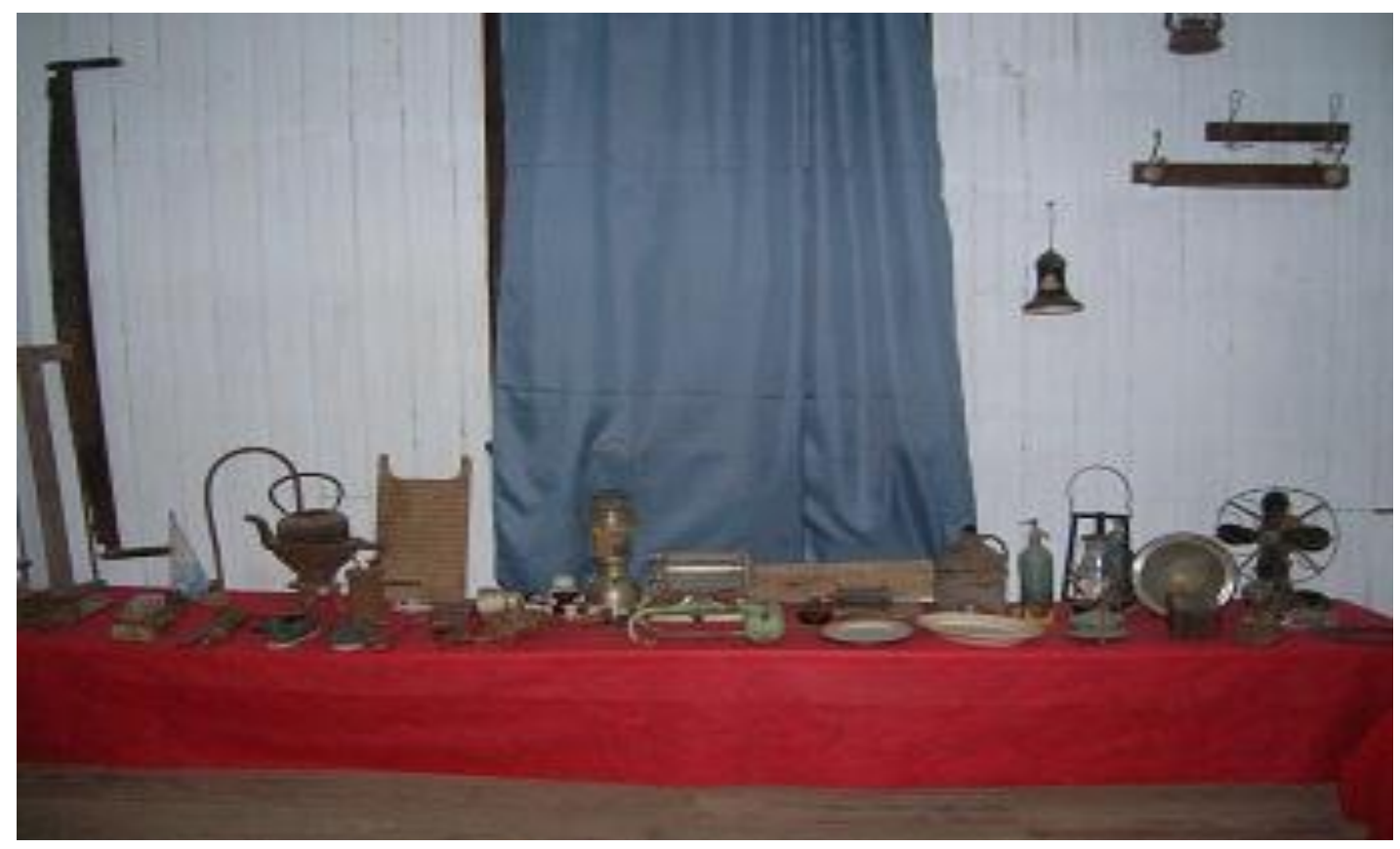

Ubicación: quinta sala.

En este espacio, se exponen algunos elementos de trabajo utilizados por los obrajeros en el monte; también se exhiben objetos utilizados en el pueblo mayoritariamente para la vida cotidiana. La guía, explica que el propósito de esa organización fue: "mostrar la diferencia de la vida en el monte, y el pueblo”. De forma sintética y descriptiva ofrece información sobre la función de los objetos, y resalta la importancia de algunos como por ejemplo la bombilla eléctrica para indicar que "el pueblo en esa época tenía electricidad”. En este espacio, que hace referencia puntualmente al trabajo y la vida cotidiana en los obrajes; el relato del guía se transforma en una descripción sucinta de la utilidad del objeto que se exhibe; como intentando circunscribir la evocación del pasado simplemente a la mención de esta actividad, sin más que decir, sin más que mostrar.

La ausencia de fotografías se produce precisamente en la sala que hace referencia a los temas que resultan más escabrosos nombrar, el trabajo de los obrajeros. Si anteriormente la guía se detenía en minúsculos detalles, para comunicar el nivel de avance y modernidad de un pueblo obrero, buscando provocar admiración en el espectador, al referirse al trabajo en el monte su discurso se vuelve sintético, descriptivo y puramente 
informativo. Cuando el relato roza el umbral de los acontecimientos pasados que incomodan recordar, es en este punto dónde las fotografías desaparecen generándose un vacío de palabra y de imágenes.

En este trabajo, de selección de fotografías, se pretende comunicar algunas memorias y silenciar otras; y se produce una irrupción en la transmisión del pasado a las nuevas generaciones. Es importante tener presente que todo acto de selección es dinámico, y que responde a motivaciones sociales vinculadas a un contexto histórico particular. Teniendo en cuenta lo mencionado, es necesario indagar sobre las condiciones sociales que posibilitan la emergencia de ciertas memorias, mientras otras son relegadas al olvido. Como sostiene Yerushalmi:

...cuando decimos que un pueblo "recuerda", en realidad decimos primero que un pasado fue activamente transmitido a las generaciones contemporáneas (...) un pueblo "olvida" cuando la generación poseedora del pasado no lo transmite a la siguiente, o cuando ésta rechaza lo que recibió o cesa de transmitirlo a su vez, lo que viene a ser lo mismo... (Yerushalmi: 1989: 17-18).

A lo largo de todos estos años la Asociación de Rescate de la Cultura Forestal, ha logrado nuclear a distintos pobladores y obtener consenso sobre el mensaje que transmite. Si bien no todos acuerdan, cabalmente, con el "gran relato" que la institución sostiene y comunica, lo cierto es que ella ha logrado aunar a los pobladores. Los integrantes de la asociación se han posicionado como gestores de memorias, los pobladores así los reconocen y colaboran aportando material al trabajo de rescate del pasado. Sin embargo, existe una minoría que no concuerdan con la visión del pasado que se transmite. Es por esto que considero necesario prestar atención al contexto en el que se produce la enunciación de estos recuerdos.

La actividad de turismo escolar es la concreción de un proyecto impulsado por la Asociación que obtuvo reconocimiento en la esfera institucional, y recibe financiación ${ }^{8}$ del Estado provincial. Para los pobladores contar con este apoyo es fundamental, porque les permite apuntar a un desarrollo turístico, y darse a conocer en la región como un pueblo con atractivo turístico centrado en su pasado fabril.

\footnotetext{
${ }^{8}$ Cabe aclarar que la financiación que reciben del Estado provincial no es total. Incluye salarios del personal que realizan actividades en el Campamento Cultural Corazón de Quebracho. En tanto que el mantenimiento del Museo, que incluye alquiler del establecimiento, es costeado por la Asociación de Rescate de la Cultura Forestal.
} 
Teniendo en cuenta esta situación coyuntural, podemos abordar las estrategias que los actores sociales utilizan en el posicionamiento de Villa Guillermina como destino turístico incipiente.

En este escenario social, en el cual el turismo emergió como una posibilidad de activación económica, los pobladores intentan comunicar un mensaje por el cual buscan ser identificados. Las imágenes por las que quieren ser reconocidos son las que evocan el esplendor de un período de trabajo y prosperidad. Estas fotografías desempeñan un papel importante en la simbología de un pueblo, situado en un contexto rural, que reivindica su origen industrial. La fábrica, con su chimenea, es el icono que representa visualmente al pueblo, identifica y sintetiza para los pobladores su trayectoria de pueblo forestal en una zona de fuerte predominancia agrícola y ganadera.

El Museo cumple una función importante, ha logrado sistematizar y formalizar una versión del pasado, las fotografías son utilizadas en función del fortalecimiento de esos recuerdos selectivos con los que los actores sociales estrechan lazos de continuidad.

La representación simbólica que se construye y transmite es la de una comunidad de trabajadores forestales felices; se apela a las fotografías de reuniones de compañeros en celebraciones sociales y eventos deportivos. En esta representación, de un tiempo pasado de bienestar social, las memorias de los trabajadores del monte no tienen cabida. En la comunicación de ese mensaje se ponen en juegos estrategias, como los silencios en el relato y las ausencias de ciertas fotografías. Es así como no se muestra en imágenes lo que no se elige nombrar en palabras.

En la última sala, se produce el anonimato del trabajador del monte. Se menciona a los obrajeros como una categoría abstracta de trabajadores, donde los nombres propios y rostros desaparecen dejando una hoja en blanco sobre el pasado. En el Museo se revela el dilema de las memorias contrapuestas, los recuerdos disidentes no encuentran cabida, en la versión del pasado que los emprendedores de la memoria sostienen Al referirse al pasado forestal evocan los buenos recuerdos asociados al trabajo y la modernidad; la exhibición de: teléfono, bombillas eléctricas, proyector cinematográfico, junto con imágenes de bailes sociales y grupos musicales, sirve para evocar un pasado de bienestar social. Sin embargo, esta selección no sólo silencia a los trabajadores del monte, quienes no fueron "beneficiados" por la empresa y tuvieron condiciones de trabajo y de vida precarias, sino 
que también silencia la agencia de los trabajadores fabriles. Este discurso hegemónico, que busca rescatar el pasado de los guillerminenses, niega la organización y la lucha de sus antepasados. Silencia las protestas obreras, las muertes de trabajadores en las huelgas de 1919 y 1920, las listas negras, la quema de las viviendas de los obreros sindicalizados, las expulsiones del latifundio de la empresa. Sintetizar los "beneficios forestales" como asistencia otorgada por la empresa anula las acciones de hombres y mujeres, colocándolos en una situación de absoluta pasividad sin dimensionar sus conquistas sociales.

En este sentido, la ausencia de fotografías, en el Museo, aporta información sobre los sentidos que los emprendedores de la memoria construyen sobre un pasado comunitario. Es importante reconocer que la construcción de sentidos sobre "la época forestal" también se produce en ambientes familiares; pero en la coyuntura actual no tienen posibilidades de visibilidad pública. La activación de las memorias depende de la agencia de los actores sociales, de sus intereses y propósitos; su emergencia pública de condiciones sociales favorables para su reconocimiento.

\section{Palabras finales}

Para concluir me gustaría citar las palabras de una joven que integra la Asociación:

\footnotetext{
Ahora, la gente nos valora más y creo que es por nuestra historia. Cuando nos visitan pueden ver que no se trata de un pueblito más, y eso se lo debemos a la Asociación, al trabajo de rescate de nuestra historia.
}

(Integrante de la Asociación)

El reconocimiento que obtienen de los otros, está situado en la valorización de la versión del pasado que comunican, es allí donde encuentra una forma de darse a conocer y de logar visibilidad social. En tal sentido recurrir a la analogía del álbum de familia, me posibilitó pensar en las fotografías que no se exhiben y no se mencionan porque irrumpen con ese ideario de familia que se intenta conservar. En el Museo las fotografías ausentes comunican tanto como las presentes, sobre todo transmiten la imagen que algunos protagonistas de este presente elaboran para ellos y para los otros. El trabajo de "rescatar" o mejor dicho de atribuir sentidos al pasado reproduce, desde la representación simbólica, la marginación social que experimentaron muchos trabajadores forestales en el pasado. Con la 
proscripción de las memorias de los trabajadores del monte, se continúa negando a esos actores sociales protagonismo en la construcción de un pasado comunitario.

Pero como el trabajo de memoria está siempre en construcción, no significa que las ausencias sean perennes. Las posibilidades de emergencia están latentes, aún sin visibilidad pública los relatos sobre la vivencias de los trabajadores del monte siguen siendo recordadas y transmitidas, claro está en entornos privados.

\section{Referencias}

AGUILAR CRIADO, Encarnación. "Patrimonio y globalización: el recurso de la cultura en las Políticas de Desarrollo Europeas". En: Cuadernos de Antropología Social, n. 21. Buenos Aires: Universidad de Buenos Aires, 2005. p. 51-69.

BALAZOTE, Alejandro; RADOVICH Juan Carlos y PRESTA, Susana. "Inversión y desinversión: consideraciones para el análisis de sistemas de producción a término". En: Espacios, tiempo y sociedades, n. 1. Luján: Universidad Nacional de Luján, 2008. p. 47-58. BRAC, Marcela. La Forestal. Experiencias de trabajo y vida cotidiana en una economía de enclave. Saarbrücken: Académica Española, 2011.

. "Patrimonio cultural y turismo emergente. Villa Guillermina, de pueblo obrero a nuevo destino turístico. Un estudio de caso". En: Cuadernos de Antropología Social, n.33. Buenos Aires: Universidad de Buenos Aires, 2011. p. 111-128.

CANDAU, Joël. Antropología de la memoria. Buenos Aires: Nueva Visión, 2002.

HALBWACHS, Maurice. La memoria colectiva. Zaragoza: Prensas Universitarias de Zaragoza, 2004.

HUYSEEN, Andreas. En busca del futuro perdido. Cultura y memoria en los tiempos de globalización. Buenos Aires: Fondo de Cultura Económica, 2007.

JELIN, Elizabeth. Los trabajos de la memoria. Madrid y Buenos Aires: Siglo XXI, 2002.

JONAS, Irene. "Mentira e verdade do álbum de fotos de familia". En: Cadernos de Antropologia e Imagem, v. 1, n. 2. Rio de Janeiro: UERJ, 1996.

PRATS, Llorenc. "Concepto y gestión del patrimonio local". En: Cuadernos de Antropología Social, n.21. Buenos Aires: Universidad de Buenos Aires, 2005. p. 17-35.

POLLAK, Michael. Memoria, Olvido, Silencio. La producción social de identidades frente a situaciones límite. La Plata: Al Margen, 2006.

RICOEUR, Paul. "Definición de la memoria desde un punto de vista filosófico". En: Academia Universal de las Culturas, ¿Por qué recordar? Barcelona: Granica, 2002.

YERUSHALMI, Yosef. "Reflexiones sobre el olvido". En: VVAA, Usos del olvido. Buenos Aires: Nueva Visión, 1989.

Recebido em: 20/04/2012

Aprovado em: 25/06/2012 